Full citation:

Hockey, J and Allen-Collinson, J (2009) The sensorium at work: The sensory phenomenology of the working body, The Sociological Review, 57 (2): 217-239.

\title{
The sensorium at work: the sensory phenomenology of the working body
}

\author{
John Hockey \\ Jacquelyn Allen-Collinson
}

Correspondence:

Dr J Hockey

School of Education

University of Gloucestershire

Francis Close Hall

Swindon Road

Cheltenham GL50 4AZ

Tel: 0044 (0)1242 714729

Email: jhockey@glos.ac.uk

Updated information :

Dr Jacquelyn Allen-Collinson

Director, Health Advancement Research Team

University of Lincoln

LN6 7TS

Email: jallencollinson@lincoln.ac.uk 
The sensorium at work: the sensory phenomenology of the working body

\section{Abstract}

The sociology of the body and the sociology of work and occupations have both neglected to some extent the study of the 'working body' in paid employment, particularly with regard to empirical research into the sensory aspects of working practices. This gap is perhaps surprising given how strongly the sensory dimension features in much of working life. This article is very much a first step in calling for a more phenomenological, embodied and 'fleshy' perspective on the body in employment, and examines some of the theoretical and conceptual resources available to researchers wishing to focus on the lived working-body experiences of the sensorium. We also consider some possible representational forms for a more evocative, phenomenologically-inspired portrayal of sensory, lived-working-body experiences, and offer suggestions for future avenues of research.

Key Words: Working body; Lived body; Phenomenology; The senses 


\section{Introduction}

From the early 1990s, research on the sociology of the body has developed rapidly to a point where there now exists a large and diverse corpus, addressing various dimensions of the body/society nexus. Indeed, 'a bewildering array of sociologies of the body' (Waskul \& Vannini, 2006, p. 2) has emerged. As has been noted, however, a systematic empirical research tradition is lacking (Ahmed, 2004; Howson, 2005; Crossley, 2007), and a literature has developed largely 'ignoring the practical experiences of embodiment' (Wainwright \& Turner, 2006, p. 238). An over-emphasis on the body as textually or discursively constituted too, can sometimes fail to acknowledge fully the corporeal dimension, both in terms of constraint and possibility, for, as Stoller (1997: xiv) points out, viewing the body as a text eliminates its sensory capacities, its odours, textures, joys and anguish. More specifically for the purposes of this paper, the sociology of the body has to an extent marginalised actual 'bodies at work' in paid employment (Hassard et al., 2000, p. 2; Wolkowitz, 2006, p. 17) (and indeed in the unpaid sector, although this latter is not the focus here), at least in terms of placing the lived working body analytically centre-stage. This statement perhaps needs some clarification. There certainly exists a gamut of occupational studies where the body is central to work performance, ranging from occupational groups for whom selling the body (or parts thereof) in various guises is integral to job performance, for example sex/erotic workers, sportspeople, dancers, models, and indeed those who literally sell their bodies in the form of blood, organs or other body parts, to those groups for whom caring for bodies is central, such as healthcare, beauty and medical practitioners, care workers, and so on. To-date, however, there have been few accounts of paid-work practices using what Crossley (1995) terms 'carnal sociology' in order to provide a more 'fleshy' embodied perspective on working bodies, where the interrelationship between social and sensory processes is explicitly foregrounded. ${ }^{[1]}$ This absence may partly be due to fact that the sociology of work and occupations has historically been pervaded by a certain 
disembodied rationality (Hassard et al., 2000, pp. 5-6; Gimlin, 2007, pp. 353-354) much of which has been inspired by Weberian and/or Taylorist influences.

In terms of the sociological analysis of the body/work nexus, as Wolkowitz points out in a recent review, there is a relative absence of studies that consider 'how it feels to be embodied, or [on] the use of the senses in employment' (2006, p. 16; emphasis added), and with the arrival of the 'sensorial revolution' (Howes, 2006) it seems to us particularly timely to address this lacuna and make these aspects more central to theoretical and conceptual analyses. Whilst an array of theoretical and methodological approaches offers useful ways to investigate the lived, sensory experience of the working body, it is the phenomenological perspective upon which we focus here, as a relative 'novelty' in the study of occupational life. Phenomenology, we contend, can offer a specific and powerful lens through which to view the 'employed' body, from both a theoretical and methodological perspective, as discussed below. Relatedly, Ehrich (2005) has signalled the potential of phenomenology (as methodology), to be used in management research, also reminding us of Sanders' (1982) earlier signalling of phenomenology as a new star on the organisational research horizon. Here we consider phenomenology - as both theoretical and methodological stance - as an addition to the many theoretical frames that can be used in examining working embodiment. This is very much a first step, and for that reason the article is necessarily schematic in sketching out the possibilities. To address our purpose, the article is structured as follows. First, a brief background is provided, citing some examples of studies that consider the working body in general, and more specifically the use of the senses at work, to highlight gaps in the literature. The case for bringing the senses more fully into the analysis of the working body is made, before some of the key theoretical resources are portrayed. We then examine movement, along with various elements of the sensory dimension of working life: the aural, visual, olfactory and haptic. The next section considers the phenomenological method and issues of representation, providing a specific example drawn from what we might term 'corporeal ethnographic' fieldnotes, in 
order to illustrate some of the phenomenological elements highlighted in the preceding discussion. We conclude with some suggestions regarding possible avenues of future research.

First then, as brief background, we note that some early studies of work and occupations did examine sensory phenomena (e.g. Garson, 1975, p. 24; Nichols \& Beynon, 1977, p. 81), but without the specific theoretical and conceptual framework later provided by the 'sociology of the body'. Although more recently the sociology of work and occupations has begun to address the working body, with some notable exceptions (see Corbett, 2006), the focus has been mainly on 'the deployment of organizational bodies, their sexuality and capacity for self-discipline' (Wolkowitz, 2002, p. 498), rather than on any explicitly sensory dimension. This gap is also highlighted in Gimlin's (2007) recent overview of the body-work relationship. An area where we might expect the sensory to feature strongly is the developing field of organisational aesthetics (e.g. Strati, 1999; Linstead \& Hopfl, 2000), but the same relative absence prevails as Mack (2007, p. 375) notes, and a recent review of the field by Taylor \& Hansen (2005, p. 1223) found few empirical examples. A research approach with potential for examining in fine-grain detail the sensory dimension of work is video-based research into employment practices (e.g. Hindmarsh \& Heath, 2007) where interesting accounts of professional 'vision' have begun to emerge. To-date however, this research has generally been published in journals focusing on human-computer interaction, as noted by Hindmarsh \& Pilnick (2002, p. 141), rather than in more sociological journals.

Turning to studies engaging formally, at least to some degree, with the sensory spectrum of work-based processes, one finds interesting and useful theoretical (e.g. Rotella, 2002) and historical (e.g. Corbin, 1986; Theweleit, 1987; Smith, 2004; Corbett, 2006) analyses. Empirical research examining embodiment via the intertwining of the social and the sensory is relatively scant though, with the majority centred on more 'feminised' occupations such as nursing (e.g. Lawler, 1991; Meerabeau \& Page, 1998; Van Dongen \& Elma, 2001; Salmon, 2002; Shakespeare, 2003), beauty therapy (Sharma 
\& Black, 2001) care work (Martin, 2002), and au pair work (Cox, 2007). Examples of other occupational groups include machinists (Kondo, 1990), glass-blowers (O'Connor, 2007), architects (Ewenstein \& Whyte, 2007), seafarers (Goodwin, 1995; Griffiths \& Mack, 2007; Mack, 2007), anaesthetists (Hindmarsh \& Pilnick, 2002; 2007), underground transport workers (Heath et al., 2002) and soldiers (Woodward, 1998; King, 2006; Lande, 2007). It should, however, be emphasized that even in this empirically-based literature, analysis of the sensory dimensions of work is rarely centre-stage, and more often constitutes a minor part of a wider analysis. Furthermore, this literature usually focuses upon a single sense rather than a spectrum of sensory activity. This relative lacuna appears an obvious one to fill, as workers become skilled in the sensory practices of their work via a combination of formal and informal learning processes, which Shilling (2007, p. 13) has termed 'body pedagogics'; processes which traditionally have been highly amenable to sociological analysis.

\section{The 'sensorial revolution'}

In sum then, the sociology of work and occupations has to-date largely neglected its topic of analysis with regard to the senses, an area of study within the social sciences that has in recent years seen a veritable flourishing, including the launch in 2006 of a new journal, The Senses and Society. Indeed, some would contend that the social sciences are currently witnessing a 'sensorial revolution' (Howes, 2006). The importance of bringing the sensory dimension in to our theorisations of the self/body/society nexus has been clearly signalled, for: 'The senses mediate the relationship between self and society, mind and body, idea and object' (Bull et al., 2006, p. 5). Such research attention is clearly overdue, as Classen (1998) and others (e.g. Geurts, 2002) have noted. This article takes a small step in highlighting the need to theorise the sensorium - the totality of the perceptual apparatus as an operational complex - within studies of work and occupations. 
It is timely therefore to address the sensorium at work, and to remind ourselves in general of 'the irremediably embodied character of ... work' (Hindmarsh \& Heath, 2007, p. 168), for as Wolkowitz (2006) argues, dealing explicitly with the embodied character of work enriches our understanding of both work and embodiment (2006), and this can be enhanced via the analysis of a central element of our working experience - the workplace 'sensed' from the standpoint of the body as the 'subject of perception' (Merleau-Ponty, 1962). It is important not only to foreground the body, but also to subject to sustained and rigorous analysis the sensory dimension of work practices. The way in which social actors carry out their occupational roles is after all an embodied process, where the senses figure prominently, and are a sine qua non for the effective accomplishment of many everyday work tasks. As Brekhus (1998, p. 36) has noted, people's everyday, practical, routine and mundane practices have all too often been left unmarked, unaccented, and taken for granted in the pursuit of more abstract, theoretical generalisations about social life. Everyday occupational task-based routines usually require a combination of complex sensory practices, and such sensory activity constitutes the phenomenological ground of 'doing work'. In order to make accurate, insightful generalisations about the ways in which work is accomplished both individually and collectively within specific work systems, and under particular employment relations, it is important for the more abstract, theoretical level of analysis to be linked to, and thoroughly grounded in, everyday, embodied occupational practices, as others have also noted (e.g. Wolkowitz, 2006). To accomplish this requires the collection and analysis of data from the working body rather than merely about it, as Shilling (2003) reminds us. The next section suggests some phenomenological, along with other relevant theoretical frames, for undertaking this task.

\section{Phenomenology and other theoretical resources}

Sensory-analytic studies are needed, we would argue, across both the sensorial and the occupational spectra, and this article can make only a small start in suggesting 
some possible lines of analysis from a phenomenological perspective. The proposed use of phenomenology, primarily existential phenomenology in this case, is not, it should be emphasized, to advocate it as the only or even the best means of investigating working embodiment, but to highlight its potential in this area. Nor is it to advocate some form of essentialist 'everywo/man' analysis, of which some forms of phenomenology have been accused, for bodies are of course subject (often severely) to structural constraints in the workplace and beyond. It should be emphasized that this article is very much a starting point, and a consideration of how key sociological variables such as gender, age, and so on, fundamentally influence the sensory component of workers' experiences also needs incorporation into future work; a point reprised in the concluding discussion. Phenomenology can, however, contribute a very useful stance on particular forms of embodiment by providing a powerful means of accessing (although never completely, as phenomenologists would emphasize), describing and analysing the experiences of individual but socially-located, socially-related and interacting bodies: gendered, classed, 'raced', sexualised, sexually 'oriented', dis/abled, and so forth (see for example, Young (1998), in relation to the gendered body). With some notable exceptions, phenomenology has rarely been applied directly to the sociological study of work and occupations (e.g. Styhre, 2004: 106; Kupers, 2005; Ehrich, 2005; Belova, 2006).

Phenomenology is of course a complex, differentiated, multi-stranded and indeed contested theoretical and methodological perspective, a veritable 'tangled web' in Ehrich's (1999) evocative imagery. Here we focus primarily upon the application of Merleau-Ponty's (1962) form of existentialist phenomenology as of particular relevance, given his long-standing concern with embodied consciousness (Meier, 1988), the body as 'being-in-the-world'. For Merleau-Ponty, the 'lived body' (das Leib) the body that links self and world in an ongoing dynamic inter-relationship, the body of everyday experience, is 'the subject of perception' (1962, p.206), socially mediated though that perception may be, including via occupational cultures. To paraphrase Merleau-Ponty (1962: 206), we are in the world through the body, just as we perceive the world with our body, so that in 
Leder's words: 'The lived body is not just one thing in the world, but a way in which the world comes to be' (1992, p. 25). Further, as Luijpen (1966, p. 50) explains, our hands are not 'any old hands', but rather are 'I-myself-grasping-things', whether these hands are employed in glassblowing (O'Connor, 2007) painting nails (Sharma \& Black, 2001) or embalming a dead body (Howarth, 1996).

Working life in general demands habituated bodily action - often highly skilled and dextrous - that becomes taken for granted, almost pre-reflective, as for example with an activity such as typing (c.f. Sudnow, 1979). Crossley neatly sums up Merleau-Ponty's position thus: 'The corporeal schema is an incorporated bodily know-how and practical sense; a perspectival grasp upon the world from the "point of view" of the body' (2001, p. 123). This practical sense is developed by habit, which is much more than a mere mechanical phenomenon, but rather, as Crossley (2001, p. 127) notes, a practical 'principle', which emerges into the social world via the formulation of meaning, intention and appropriate action. Consequently, workers have an understanding that is not just cognitive but also corporeal, developed by bodily engagement in habitual, quotidian work practices. Merleau-Ponty's work certainly offers a powerful stance from which to analyse working embodiment. In order to capture more fully work-based embodiment (although recognising that 'fully' capturing the totality of such embodiment remains an impossibility), other kinds of intellectual resources can also be brought to the analytic table, in order to 'flesh out' the theoretical framework; some of these are considered below.

Moving to other theoretical resources, Shilling (2007, p. 12) reminds us, anthropology has probably conducted the most sustained and detailed investigations into the bodily practices of social groups which have tended to escape the sociological gaze, and this would certainly apply to many occupational groups. Of particular salience in the analysis of working embodiment is a developing anthropology of the senses (e.g. Classen, 1997a; Howes, 2003) and to some extent an emergent 'sensuous geography' (Rodaway, 1994). As Howes writes in relation to the power of a sensory ethnography: 
'The senses are theorized as mediating the relationship between mind and body, idea and object, self and environment (both physical and social)' (2001, p. 122); a theorisation directly relevant to the occupational sphere, as workers move, see, hear, feel, touch, and smell during the routine performance of daily work. These sensory dimensions work in concert (Howes 2003, p. 47) to generate the direct, lived-body experience, the phenomenology of working activity. The current lack of phenomenologically-inspired analyses of working practices within the sociology of work/occupations is perhaps surprising, given how strongly the sensory dimension often features in work experiences. Workers are after all 'sensible sentients' (Merleau-Ponty, 1962) both seeing and seen, hearing and heard, touching and touched, and so on within their occupational milieux. To begin to address this research lacuna, this article depicts a range of sensory work activities, employing some of the theoretical resources previously highlighted. What we offer here is far from a comprehensive listing (taste is not examined here, for example, and is fundamentally linked to the olfactory), and necessarily somewhat schematic, providing a fleeting flavour of what the approach might offer. At this juncture then, we merely put forward some ideas for incorporating the sensorium in greater depth into studies of work and occupations.

\section{Movement and the sensory dimension of workplace embodiment}

Before considering the role of the senses in workday, workplace experiences, we provide a brief discussion of three inter-related elements intrinsic to that experience: movement, rhythm and timing.

\section{Movement, rhythm and timing}

Commensurate with the phenomenological interest in time and space, and although varying enormously in degree and extent, movement is central to most working practices, whether requiring the slight movement of a computer mouse, the dexterity of keyhole surgery, or ranging over miles in order to deliver mail. Indeed, movement of some kind is intrinsic to all work practices, however tightly management may attempt to control 
workers' range of movement and to limit the space around which they are free to move (Baldry, 1997). Importantly too, movement is linked to feeling, so that it has been argued that: 'It is movements that trigger sensory activity that the consciousness in turn experiences as feelings' (Tangen, 2004, p. 21). For analytic purposes, it is possible to categorise 'work moves' into two components: rhythm and timing, which are symbiotic. For some occupational groups, rhythm and ability to generate, use or control it, is an explicit requirement of the job, for example with dancers and musicians. Each employment context has its own particular rhythm, so for example, factory workers faced with the inexorable rhythm of 'the line' and the repetitive nature of their tasks, work to a predominantly cyclical and relatively constant rhythm (Cavendish, 1982), whereas working in a café may involve a stop-start rhythm, with the ebb and flow of customers throughout the working day (Laurier, 2008), whilst other occupations such as farming are more aligned to seasonal rhythms. Analytically it becomes possible to define corporeal rhythm in general as a: "patterned energy-flow of action, marked in the body by varied stress and directional change; also marked by changes in the level of intensity, speed and duration' (Goodridge, 1999, p. 43). To accomplish such rhythm, participants must skilfully coordinate their bodies, often in time with co-workers or machinery, and the complexities of that coordination vary considerably between different kinds of work. So, arguably, dancers or builders may require greater full-body coordination than would, say computer operators, or workers in a telesales call centre (Whalen et al., 2002), as the former have to make manoeuvres through larger and more diverse planes of movement.

To achieve these movements competently often necessitates the development of a particular sense of timing. The precision of the farrier's hammer swing, the delicate cushioning of a (soccer) football on a professional player's chest, or the passing of surgical instruments between hospital operating theatre staff (Hindmarsh \& Pilnick, 2007, p. 1404) all require expert timing, which Goodridge (1999, p. 44) defines as: 'the act of determining or regulating the order of occurrence of an action or event, to achieve desired results'. This embodied sense of rhythm and timing requires a highly developed 
awareness of sensations emanating from organs, particularly the skin, ligaments, tendons and muscles as they move; in effect an assemblage of 'immediately lived sensations' (Leder, 1990, p. 23), which provides feedback on body position, balance, pace and so on.

Having noted the importance of movement, the analysis now moves to examine various sensory dimensions of the work-body experience: the aural, visual, olfactory and haptic. This is necessarily indicative and suggestive, rather than comprehensive; it should for example be noted that the analysis focuses upon workers with use of all their sensory capacities - research might very usefully examine how workers without one or more senses engage in the practice of their occupation.

\section{Listening and hearing}

For some occupational groups a keen sense of hearing is a pre-requisite for work performance. Musicians, singers and sound engineers, for example, usually rely on a highly developed and sophisticated auditory capability, although this is not a universal requirement, as evidenced by Dame Evelyn Glennie, the deaf solo percussionist. In relation to sound in general, Rodaway notes that it, 'is not just sensation: it is information. We do not merely hear, we listen' (1994, p. 95), including listening to our own working bodies, and their respiratory patterns. The habitual lifting of heavy sacks all working day, for instance, teaches workers to pace themselves by listening and attending to their breathing (Nichols \& Beynon, 1977). Even in arguably less physically-dynamic kinds of work, effective action often demands hand-eye and respiratory coordination, as tense, erratic breathing can have deleterious effects upon bodily control and working performance, for example when performing delicate surgical or dental operations where steady, even respiration helps ensure steady hands (and nerves). Singers, actors, politicians and lecturers must control respiratory patterns in order to project their voices effectively. Furthermore, in relation to the somatic/social nexus, respiratory patterns are co-related with emotion or feeling states and social action, as Lyon (1997, p. 96) notes. The emotional, social and interactional elements of doing work may then be connected to 
respiration, which becomes particularly significant in teamwork contexts, where members have physically to synchronise or co-ordinate movements, for example, in professional sports teams, and among soldiers (King, 2006). Workers may have to listen not only to their colleagues' breathing, but also to that of their customers, clients or patients, as a change in respiratory rate may signal pain, physical or psychological distress, even imminent or actual death (Meerabeau \& Page, 1998). This has to be measured and monitored with great intensity in some working environments, such as operating theatres or intensive care units where machines provide both visual and auditory signals as indicators of patients' bodily states. Extensive practice at working with equipment or tools of various kinds often provides the user (or repairer) with an acute awareness of the sounds they produce during optimal or sub-optimal performance, or imminent breakdown, such as on factory production lines (Cavendish, 1982).

\section{Occupational vision}

Ocularcentrism is perhaps a legacy of the Kantian hierarchical ranking of the senses, in which the three 'higher' senses of touch, sight and hearing were separated from the two 'lower' senses of taste and smell, on the basis of their 'objectivity'. Kant considered that when humans employ the lower senses they are more aware of the organ than of the object of sense. For Kant, the sense of sight was the noblest (1978, p. 43; quoted in Curtis, 2008, p. 10). As has been theorised, particular social groups have distinctive 'ways of seeing', and Goodwin argues for particular forms of occupational and professional vision, the 'socially organized ways of seeing and understanding events that are answerable to the distinctive interests of a particular social group' (1994, p. 606). This stance is clearly supported by Bittner's (1967) work on the police, together with more recent research on hospital operating theatre staff (Hindmarsh \& Pilnick, 2002; 2007) and underground transport workers (Heath et al., 2002). Commensurate with the phenomenological perspective, what is actually 'seen' in these situations is of course heavily dependent upon experiential knowledge. Ways of seeing are structured and mediated by cultural forms, and by specific kinds of knowledge, which are in turn 
informed by the act of seeing itself, in a complex circular process. On the basis of that vision and its interpretation, a course of action is selected from a myriad of potential actions. For example, the visual evaluation of level and type of snowfall is taken into account variously by mountain rescue teams, ski instructors, and professional skiers when deciding how to approach a snowbound route. The work of painters (artists and decorators) and television engineers requires the ability to gauge and precisely differentiate colours and to alter these by almost imperceptible degrees; colour perception has long constituted a topic of interest within phenomenology (e.g. Junichi, 2005).

As Emmison and Smith comment: 'Environments are not simply places where we see things in a passive way. They are also locations where we must look in active ways' (2000, p. 185). Workers look and see in active ways so as to make sense of the contexts, physical and social, in which they labour. Moreover, as noted earlier, engagement in work usually demands movement, and as Ingold (2000) reminds us, 'people see as they move' (p. 226) and, 'our knowledge of the environment undergoes continuous formation in the very course of [our] moving in it' (p.230). The workplace terrain is thus seen, interpreted and evaluated via a stock of occupational knowledge. So research questions relating to the visual might cohere around the development of occupational vision and its impact upon working performance; for example: how do explosive experts see buildings that they are commissioned to demolish? What is the relationship between how infantry soldiers see and act upon the spaces in which they move, or the spaces into which their comrades are moving, when out on patrol in Iraq or Afghanistan? What impact does this way of seeing have on the social organisation and performance of patrols?

\section{The olfactory dimension}

As Curtis (2008) notes: ' ...smell, and the organs that make it possible, occupy an inferior place in dominant approaches to the senses, which continue to embrace the sensory hierarchy articulated in Kantian rationalism' (p. 6). Indeed the olfactory 
dimension of embodiment in the workplace has rarely been analysed, as Corbett (2006) notes in calling for organisational researchers to 'take smell seriously'; for this reason we accord it a little more space. In some occupational groups, 'the nose' is essential to effective occupational performance. Perfumers, chefs, sommeliers/sommelières, flowergrowers, and tasters of all kinds from chocolate to tea, all require a refined olfactory capacity and skills in order effectively to carry out their work tasks. On another dimension, work deemed more 'manual' and demanding of whole-body input is often intimately connected with sweat and a certain kind of pungency that permeates the toiling body. Whilst levels vary across economies and sectors, for the vast majority of human beings, work still means hard labour (Styhre, 2004, p. 110), and for many workers, the smell (and sensation) of sweat on skin testifies that the body is engaged in demanding labour. The moral order of odour may then be corporeally and symbolically correlated with the 'right' degree of effort, with actively 'earning one's pay'. Further, it may also function to substantiate work identity, for as Synott (1993, p.190) indicates: 'odour is a natural sign of the self as both a physical and a moral being. The odour is a symbol of the self'. Although strong body odour has traditionally been associated with a discredited moral status, being a 'stinker' or 'skunk' (Largey \& Watson, 1972), it may also transmit other messages within the social spaces of work, including the message that one is not slacking.

More 'disagreeable' olfactory input provides workers with messages of mutual affirmation and/or disgust at having to encounter unpleasant smells as an integral part of working life, for example the stench of fish that greets cannery workers, the complex synthesis of smells that farm-animal veterinary surgeons routinely encounter (Hamilton, 2007, p. 490), the smell of bodily fluids confronting doctors and nurses (Bolton, 2005), mortuary workers, and even attendants of locker rooms where, 'naked bodies also excrete body fluids from various orifices, drop hair, spit, and shave' (Fusco, 2006, p. 7) Other smells generally coded as more agreeable, such as the whiff of soap powder and starch in commercial laundries, the metallic tang of gas burnt off in steel mills, the smell 
of oil and grease on a mechanic's overalls, all work to confirm the self's involvement in the working present, and also, importantly, to substantiate the working past and thus identity, via memory. Tuan (1993, p. 57) notes the capacity of smells vividly to invoke memories, positive and negative: 'Odour has the power to restore the past because, unlike the visual image, it is an encapsulated experience that has been left largely uninterpreted and underdeveloped'. Particular aromas can powerfully evoke the working past, and fuse it with the emergent present, as memories collide with the here and now of the body engaged in employment, or indeed unemployment or retirement.

It seems plausible too that different forms of work have different 'smellscapes' (Classen et al., 1994, p. 97); an amalgam of aromas that changes according to space, place and specific activity, and also to seasonal and temporal conditions, for example in farm work, or for teachers returning to work after a vacation, encountering the evocative mix of floor and furniture polish. Currently there appears to be a dearth of systematic sociological documentation of such 'panaromas' in relation to their impact upon working people and practices, although tantalising glimpses appear in the literature, such as Form's (1973) reference to autoworkers preferring the noise and smell of the factory to the more 'dainty' but dull routines of the office. There have also been studies of the beneficial effect of aroma in reducing stress levels among workers such as nurses (Davis et al, 2005) and the rising popularity of aromachology (the effect of smell on human behaviour), testifies to the notion that certain fragrances can boost productivity (Corbett, 2006, p. 227). Further, Psathas (1979, p. 224) has identified how maps are read as a 'set of sequential particulars', such as hills, valleys, road junctions, etc. Perhaps too particular stretches of occupational terrain, within a factory, hospital or a school, for example, harbour sets of aromatic sequential particulars, which workers use to 'order their experience and understanding of space' (Classen et al., 1994, p. 98) and of time. 


\section{The haptic}

The final sensory dimension we consider here is the haptic, defined by Rodaway as: 'a combination of tactile and locomotive properties [which] provides information about the character of objects, surfaces and whole environments as well as our own bodies' (1994, p. 48). Merleau-Ponty (1962) highlights the importance of tactile experience in embodiment and, interestingly, as Classen (1997b) notes, the more 'corporeal' senses of smell, taste and touch have often been linked with women and female values, in the gendered hierarchy of the senses. The study of touch between workers and their colleagues, customers, clients and patients already has a relatively developed literature especially regarding occupations such as care work and beauty therapy (see for example, Twigg, 2000; Sharma \& Black, 2001, respectively). Here, we briefly consider the less researched area of physical interaction between working bodies, terrain and objects. For many, work involves haptic interaction with the occupational 'terrain', whether that be (literally) the factory floor or the sea, and with equipment, ranging from huge objects such as fishing vessels and earth-moving diggers, to smaller items such as the finely graded brushes of make-up artists. The worker's touch is mainly an active one, combining pressure between the working body, the terrain of work and equipment or tools, together with a kinaesthetic awareness of the body as it moves through planes. 'Touch is, therefore, about both an awareness of presence and of locomotion' (Rodaway, 1994, p. 42). In addition, humans use touch as confirmatory, to remove doubt, as Hetherington (2003) has noted. It is a directly embodied way of feeling and experiencing the world, and seeking to understand its properties. The human body itself may constitute the subject, object and terrain of working practices, particularly for medical, health and beauty practitioners, who rely extensively on touch to change, heal, manipulate and reassure (Sharma \& Black, 2001; Van Dongen \& Elma, 2001).

Using their haptic resources, workers 'tune in' (Ingold, 2004, p. 332) to their working environments, engaging with particular work terrain, including tools and objects. 
As Leder (1990, pp. 15-18) has noted, touching and seeing are closely linked in many cases - computer operating would be a classic example of such ocular/haptic coordination. Corresponding to Merleau-Ponty's (1962) notion of 'reversibility', just as workers actively touch, they are also in turn touched by the physical properties of the working terrain, including workplace objects, and thus develop a two-way, embodied relationship with them (c.f. Hindmarsh \& Heath, 2000). The use of a hammer, for example, sends vibrations into the body of the user, which provides sensory input that is used to inform decisions on action and technique. Perhaps not surprising, given the importance of the hands in many occupational spheres, 'studies of haptic perception have focused almost exclusively on manual touch', as Ingold (2004, pp. 330-331) points out, calling for studies also to examine 'techniques of footwork'. This call is particularly apposite for a phenomenological exploration of occupational groups engaged in professional sports such as soccer, athletics, and dance, but also in certain kinds of therapeutic massage (e.g. Tui $\mathrm{Na}$ ), using foot work.

The above sections have provided a very fleeting entrée into the potential of sensory analysis to contribute new insights into the study of the body at work. We now consider the phenomenological method specifically, and some of the ways in which this form of analysis might be used further to investigate and portray the sensuous working body.

\section{The phenomenological method, corporeal ethnography and representation}

The phenomenological 'method' is perhaps better described as a phenomenological attitude, an orientation to the world, a way of looking, 'an attitude of attentiveness to the things of immediate experience' (Van den Berg, 1972, p. 77, quoted in Kerry and Armour, 2000, p. 8), rather than any set of prescribed techniques or procedures, although these have indeed been advocated by some. For many phenomenologists, however, any method that can produce detailed, rich, in-depth, textured, descriptions of participants' subjective, concrete lived experiences of a 
phenomenon, has the potential to provide the basic data for application of phenomenological analysis as Katz and Csordas (2003, p. 277) indicate in the case of anthropologists working in this tradition. In general, phenomenologists use the processes of epochē (bracketing, as far as possible, of taken-for-granted assumptions) and eidetic reduction in an attempt to access the essential structures of an experience.

There is, however, a vast range of ways in which phenomenological research has been/might be designed and conducted, with a rapidly developing literature now in existence. Interestingly, though, phenomenology's relationship to sociology has been contentious and marginal, particularly in its ethnomethodological form, as inspired by the writings of Husserl and Schutz (Pollner \& Emerson, 2001). Katz and Csordas (2003, p. 282) go so far as to characterise phenomenological sociology as a 'flickering light', although this light has been cast in interesting sociological ways, for example in the sociology of 'impairment' (Paterson \& Hughes, 1999). In contrast, there has been a veritable burgeoning of phenomenological psychology particularly within health psychology (e.g., Moustakas, 1994; Willig, 2007), in which there have been numerous and varied attempts at operationalising phenomenology in a specific empirical approach. Interpretative Phenomenological Analysis (IPA) for example has been extensively utilised within psychology and health and medicine-related studies. Here, semistructured interviews and forms of thematic content analysis are often used to examine participants' understandings, perceptions of, and beliefs about a phenomenon (see for example, Chapman and Smith, 2002). With some of these studies, however, it must be said that at times they are difficult to distinguish from qualitative research in general, especially where there is scant, if any, reference to phenomenology or phenomenological principles per se. Examples of phenomenological research that do respect a phenomenological ethos are provided by van Manen (1990) (hermeneutic perspective on pedagogy), Todres (2007) (in relation to psychotherapy), Moustakas (1994) and Giorgi (1985) (using existential perspectives). Van Manen's (1990) hermeneutic phenomenology is directed to understanding aspects of the lifeworld in 
order to examine their pedagogical significance and implications. Giorgi's (1985) phenomenological method uses a Husserlian-inspired approach in order to address psychological problems, and he provides detailed guidelines for undertaking phenomenological research (for a good summary, see Willig, 2008, p. 55). Researchers vary greatly in the degree of phenomenological 'reduction' or distillation undertaken and also the extent to which they apply theoretical, 'scientific' or their own language constructs to the structures of experience recounted by their participants, mindful of Husserl's (1931) own exhortation to bracket such 'scientific' explanations and understandings. For, as Willig (2007, p. 216) reminds us, 'the researcher's choice of label for the phenomenon of interest is not merely a descriptive act but a constitutive one'.

With regard to data collection, in addition to the semi- or unstructured interviews mentioned above, we propose some additional means by which data amenable to phenomenological analysis might be obtained. The first is not a particularly unorthodox strategy, and involves a dual-phase, researcher-participant approach, as suggested by Coe \& Strachan (2002) in their research on dance. The initial data-recording phase involves the researcher's observation of the embodied activity and the recording of the movement sequence(s), whether by video (Hindmarsh \& Heath, 2007), film, or notation. This might be, for instance, a depiction of the embodied routines of a glassblower (c.f. O'Connor, 2007) as s/he produces a glass object. The researcher then presents the observational data to the participant, who points out from her/his own lived-body perspective the key points of physical effort within the sequence. Coe \& Strachan (2002) suggest that the participant examines the narrative of this joint production, adding in sets of personal meanings correlated with each phase of effortful movement; it is at this point that the rich depiction of the relevant sensory data becomes possible. Coe \& Strachan advocate an evocative depiction, a salient point when one remembers that within the phenomenological approach 'the purpose of writing is to bring the essences of the lived experience into being' (Kerry \& Armour, 2000, p. 9). 
In relation to such evocation, a second means we consider is the use of an autoethnographic approach. Extracts from auto/ethnographic fieldnotes taken in a particular occupational context are provided below by way of an example, but first we note that there currently exists a small but developing corpus of autoethnographic research focussing upon occupational lives (e.g. Hinckley, 2005; Mischenko, 2005; Taber, 2005; Adams, 2007; C \& O, 2007); a genre which fuses author, researcher and researched. Authors within this genre appear to be willing to take certain 'risks' with their representational forms, often constructing narratives that portray in evocative fashion their phenomenological experience. Little of this material, however, applies the theoretical and conceptual resources portrayed above, although some authors do implicitly adopt elements of a Merleau-Pontian (1962) perspective, in terms of the body as 'subject of perception', for example.

Writing and representation are fundamental concerns within phenomenology, for in order to bring to life the essences of lived experience for the reader, to engage in 'the breathing of meaning' (Van Manen, 1990, p. 36), the researcher/writer must convey accurately, powerfully, evocatively and some would advocate aesthetically (but always inevitably only partially), the phenomena described, whether via writing or other re/presentational forms. To-date, there have been few attempts to analyse and portray in such evocative fashion the sensory elements of the lived work-body. In part this may stem from the problem of accessing the embodied mind (Bain, 1995), as phenomenologists have long sought to do, but also there may be perhaps a reluctance on the part of many academic writers, including those within the fields of work and organisations (Mack, 2007, p. 377), to deviate from a form of communication which gives precedence to the 'disembodied author' (Sparkes, 2002). As a consequence, as Eliasoph indicates: 'Sociology's "realist" writing genre might not be up to the task' (2005, p.163). Analogously, Highmore, in discussing the connection between expression and experience in everyday life notes: 
'For an approach to everyday life that specifically wants to foreground the sensual realm of smells, gestures, and tastes, the question of expression will not resolve itself through recourse to already established forms of sociological presentation' (2004, p. 318)

Thus, a certain representational orthodoxy has failed to capture and portray evocatively the phenomena of sensuous experience, means that the analytic depiction of working embodiment is still found wanting in some directions, or undertaken in the awkward disembodied impersonal writing style favoured by the vast majority of academic journals' (Corbett, 2006, p. 229). Evocatively to portray sensuous occupational practices requires what Taylor \& Hansen (2005, p. 1225) term 'thick sensory description'. The best way to illustrate this is perhaps via an example of some corporeally-grounded auto/ethnographic data. Below we provide extracts from what might be term 'corporeal ethnographic' field notes, gathered by the first author during participant observation in a specific occupational context, the UK Infantry. ${ }^{[2]}$ The fieldnotes portray a particular, highly embodied activity for which the infantry habitually trains: 'tactical advance to battle' (TAB), which involves long marches carrying weapons and bergens (rucksacks) full of equipment and ammunition, routinely weighing in excess of 80 pounds. The specific context was a military training area in Alberta, Canada. Each fieldnote aims to demonstrate an increasing engagement with the phenomenological and corporeal elements of the field, commencing with the least 'embodied' level:

Today the Company has been marching in two long adjacent lines down mostly undulating sandy trails for 20 miles. This has been a long TAB which has tested everyone, as the ground is difficult, temperatures high, and we are carrying full operational loads. There is no relaxation of tempo which is driven by the shouts of NCOs, and the final irritant a chopper [helicopter] passing back and forth covering us in dust.

This description is essentially informational, containing little about the phenomenological impact of the work activity. The next extract begins to provide some evocation of the corporeal experience of infantry work: 
Today has been tough with another big TAB, everyone is on their 'chinstraps' [exhausted], little chatter after the first five miles, all energies devoted to keeping going, you can see it in 'the lads' (and presumably mine) eyes. Drawn faces, moving forward in the classic infantry shuffle, bowed down under the loads. All the muscles moan, everything aches. Covered in crap.

Delving yet further into the phenomenology of the working lived-body, the final extract focuses much more directly on the sensory dimension of the lived body:

Bergens get pulled on for another TAB, uuuuuuhhhhh, breath exhaled as load hits the body, spine feeling driven down to earth, feel vertebrae CLUNK! Our faces all screwed up tight, eyes clenched closed initially as the load bites, my mind shouts no! - not more today. Move: yesterday's blisters say 'good morning!', who's put a lighted match to shoulders?? (shift load find a better position - there is none), toes, heels (blood in boots not a myth), hips (ammunition pouches) rub rub rub. Bite bite lips it helps... Neck muscles grabbed by a monster who is twisting them tighter, tighter. Biceps and forearms plead 'rest' so change weapon to other arm ...Tongue huge in mouth, foul dry saltness, can't spit, back all wet sweat, and crotch same so SORE, chopper [helicopter] dust in eyes so same SORE. Who's shooting electricity into knee hinges? 2 (miles) to go, calf muscles zing zing with cramp, thighs same - surges of buzzing, whirring sharpness going through them, up a rise panting like a lot of cattle, blow snot, close eyes again, try put mind in neutral, focus, bent forward, can only see 10 yards of trail. Finish, there are the brew (tea) and medics wagons, I'm KNACKERED, just me, nah just everybody - 'you know what its like now', the lads say, 'you must be daft to be here!'.

Whilst each of the fieldnote extracts above provides some information about the experience of working activity, it is only the third that combines sufficient detail of bodily processes and depth of narrative evocation to constitute an example of Taylor \& Hansen's (2005, p. 1225) 'thick sensory description'. This last textual form begins, in a small way, evocatively to portray what Leder has termed the body's 'ceaseless stream of kinaesthesias, cutaneous and visceral sensations' (1990, p. 23). We would contend that this kind of narrative, providing a depth of sensory representation, can provide a certain level of analysis and evocation in depicting the phenomenology of the lived-body in occupational work. This form of analysis can then complement other kinds of theoretically- and methodologically-framed accounts in order to give a more corporeallydetailed and rounded picture of working embodiment.

\section{Concluding Discussion}

Given the relative lack of studies seeking to chart the complex sensory practices that underpin everyday, occupational task-based routines, there is, we argue a need for 
research attention to be paid to the phenomenological ground of 'doing work', especially in relation to the sensorium. For workers often become highly skilled at specific forms of movement and the manipulation of objects essential to their occupational practices. The deployment of such skill requires the development of a spectrum of sensory intelligence, employed to execute skilful, practical, working action. The fusing of knowledge and action gradually becomes, over time and with much practice, embodied and largely taken for granted. As Leder (1990, p. 31) notes: 'A skill is finally and fully learned when something that was extrinsic, grasped only through explicit rules or examples, now becomes to pervade my own corporeality', and of course such skills may never truly be fully learnt once and for all, but require regular practice and updating. Further, although these skilled actions may be repeated a vast number of times, their reproduction is never identical because the environment changes, demanding improvisational adjustment and readjustment, accomplished via ongoing sensory input and the monitoring of conditions (c.f. Ingold 2000, p. 353). The working environment may, depending upon the nature of the occupation, require engagement with particular kinds of terrain, equipment, meteorological conditions, other workers, clients, customers, patients, and so on. Skill at work (and more generally) is not merely 'an isolated ability in a person's body, but is better understood as a meshing of a person's intentions, through their abilities with the environment (including other people), already interrogated by a skilful person for significant information' (Ingold, 2000, p. 353 et seq.).

As previously noted, there is a dearth of sociological research at the level of sensuous corporeality (Crossley, 2007, p. 84), and this is certainly the case in relation to work and organisations (Wolkowitz, 2006, p. 16); a research terrain that Styhre (2004, p. 110) describes as terra incognita. Currently, there is little sociological analysis of the specific occupational ways of bodily monitoring, comportment, movement and sensing, for example, examining how bricklayers move, financial traders see computer screens, call-centre workers hear, acupuncturists touch, and so on. What are these workers' particular occupational 'somatic modes of attention' (Csordas, 1993, p. 138)? Similarly, 
little is known about the process of corporeal interaction when people work in teams (Hindmarsh \& Pilnick 2002), what we might term, following Merleau-Ponty's (1969) terminology, their occupational inter-corporeality. For example, how do aircraft crews, surgical teams, and dentists and dental assistants accomplish their cooperative, highly coordinated, embodied routines? These individual and collective corporeal processes constitute some of the fundamental elements of work, and so allow its ordered practice. As Lynch (2001) highlights, what is really at stake is not so much the theoretical problem of order but the substantive production of order on singular occasions. This production of order is, for many workers, routinely repeated on each working day via the enacted synthesis of skilful sensory practices.

We have suggested just two potential ways of capturing something of the phenomenology of the working body, in order to offer insight not only into the individual's meaningful working embodiment but also into the ways in which workers share embodied experience. These are certainly not the only means. For instance, in order further to extend and develop the analysis, a strategy might be to compile a series of accounts of the sensuous activity intrinsic to a particular occupation. Such accounts could be used to generate a set of inter-linked analytic categories. The nature of that linkage and its consequences could then be interrogated; for example, how do tailors see and touch cloth and their tools of the trade, using their own sub-cultural understandings? What are the consequences for performance of that human-equipment interaction? It might then be possible to use these analytic categories to compile an agenda for interviewing a cohort of experienced tailors. In this way, a sociology of tailors (a sartorial sociology?) could be built upwards from a bedrock of embodiment, thus explicitly connecting grounded empirical data to theory. As Eliasoph notes: 'theory usually demands close, logical argumentation' (2005, p. 166) and one of the key challenges for the sociology of work and occupations is the synthesis of abstract theorisation with evocative analysis, to capture (partially at least) the sensory dimensions of the working body. Abstract generalisations regarding embodied, sensory work activity - its corporeal ups and downs, 
joys and pains - might then be analytically grounded in the actual activity rather than remaining somewhat disconnected. Analytic depictions of the sensory work that constitutes the phenomenological ground of occupations, together with its organisational contextualisation, are needed to explore and explain the ongoing construction and maintenance of the order of occupational work.

This paper has suggested some ways in which a phenomenologically-inspired analysis might begin the dénouement and evocative-analytic portrayal of the sensory dimensions of occupational/organisational bodies. Analysis at the sensory level is of course only one dimension, but then other kinds of occupational research are also partial (Mack, 2007, p. 377). As noted too, phenomenology is only one amongst numerous potential theoretical and methodological avenues, and this article is merely a starting point; a fleeting flavour of phenomenological possibilities. Future phenomenologicallyinspired studies might well give consideration to the ways in which some of the key sociological variables of gender, age, class, ethnicity, dis/ability, and so on, intersect, fundamentally to influence the sensory component of workers' experiences. Synthesizing the different levels and forms of analysis is indeed a challenge, and given the current lacuna, a research focus upon the sensuous experiences of the lived working body, including the academic body, is long overdue. As Corbett (2006, p. 229) reminds us: 'Research is an embodied task and an aesthetic experience whether we like it or not', and so the phenomenology of the sensorium is central to many everyday work practices, including those of academic researchers.

\section{Notes}

1. The article focuses upon the sociology and social phenomenology of the body/work nexus and therefore does not include studies that would fall under the remit of the psychology of work and organisations. 
2. Subsequently published as an occupational ethnography, Author - to be inserted post-refereeing. 


\section{References}

Adams, V. (2007). Laughing it off: Uncovering the everyday work experiences of nurses. International Journal of Qualitative Methods, 6 (1), 1-15.

Ahmed, J. (2004). Reaching the body: Future directions. In H. Thomas and J. Ahmed (Eds), Cultural bodies: Ethnography and theory (pp. 283-300). London: Blackwell.

Bain, L. L. (1995). Mindfulness and subjective knowledge. Quest, 47, 238-253.

Baldry, C. (1997). The social construction of office space. International Labour Review 136, 365-78.

Belova, O. (2006). The event of seeing: A phenomenological perspective on visual sense-making. Culture and Organization, 12 (2), 93-107.

Bittner, E. (1967). The police on Skid Row: A study of peace keeping. American Sociological Review, 32 (5), 699-715.

Bolton S. (2005). Women's work, dirty work: The gynaecology nurse as 'other'. Gender, Work and Organisation, 12 (2), 169-186.

Brekhus, W. (1998). A sociology of the unmarked: Redirecting our focus. Sociological Theory, 16 (1), 34-51.

Bull, M., Gilroy, P., Howes, D. \& Kahn, D. (2006). Introducing sensory studies. The Senses and Society, 1 (1), 5- 8.

Cavendish, R. (1982). Women on the line. London: Routledge.

Chapman, E. \& Smith, J.A. (2002). Interpretative Phenomenological Analysis and the new genetics. Journal of Health Psychology, 7(2), 125-130.

Classen, C. (1997a). Foundations for an anthropology of the senses. International Social Science Journal, 153, 401-20.

Classen, C. (1997b). Engendering perception: Gender ideologies and sensory hierarchies in Western history. Body \& Society, 3 (2), 1-19.

Classen, C. (1998). The color of angels: Cosmology, gender and the aesthetic imagination. London: Routledge.

Classen, C., Howes, D., \& Synott, A. (1994). Aroma: The cultural history of smell. London: Routledge.

Coe, D., \& Strachan, J. (2002). Writing dance: Tensions in researching movement or aesthetic experience. International Journal of Qualitative Studies in Education, 15 (5), 497-511.

Corbin, A. (1986). The foul and the fragrant. Cambridge, MA: Harvard University Press.

Corbett, J. M. (2006). Scents of identity: Organisation Studies and the cultural conundrum of the nose. Culture and Organization, 12 (3), 221-232. 
Cox, R. (2007). The au pair body: Sex object, sister or student? European Journal of Women's Studies, 14 (3), 281-296.

Crossley, N. (1995). Merleau-Ponty, the elusive body and carnal sociology. Body \& Society, 1 (1), 43-63.

Crossley, N. (2001). The social body: Habit, identity and desire. London: Sage.

Crossley, N. (2007). Researching embodiment by way of body techniques. Sociological Review, 55, Supplement 1, 80-94.

Csordas, T. J. (1993). Somatic modes of attention. Cultural Anthropology, 8 (2), 135156.

Culture and Organization (C \& O) (2007) Special Issue: Organizational autoethnography. $13(3)$.

Curtis, B. (2008). 'I can tell by the way you smell': Dietetics, smell, social theory. The Senses and Society, 3 (1), 5-22.

Davis, C., Cooke, M. Hozhauser, K., Jones, M., \& Finucane, J. (2005). The effect of aromatherapy massage with music on the stress and anxiety levels of emergency nurses. Australasian Emergency Nursing Journal, 8, 43-50.

Ehrich, L.C. (1999). Untangling the threads and coils of the web of phenomenology. Education Research and Perspectives, 26 (2), 19-44.

Ehrich, L.C. (2005). Revisiting phenomenology: Its potential for management research. In Proceedings, Challenges or organisations in global markets. British Academy of Management Conference, pp. 1-13. Said Business School, Oxford University.

Eliasoph, N. (2005). Theorizing from the neck down: Why social research must understand the body acting in real space and time (and why it's so hard to spell out what we learn from this). Qualitative Sociology, 28 (2), 159-169.

Emmison, M., \& Smith, P. (2000). Researching the visual. London: Sage.

Ewenstein, B., \& Whyte, J. (2007). Beyond words: Aesthetic knowledge and knowing in organizations. Organization Studies, 28 (5), 689-708.

Form, W. H. (1973). Auto workers and their machines: A study of work, factory, and job satisfaction in four countries. Social Forces, 52 (1), 1-15.

Fusco, F. (2006). Spatializing the (im)proper subject: The geographies of abjection in sport and physical activity space. Journal of Sport and Social Issues, 30 (1), 5-28.

Garson, B. (1975). All the livelong day: The meaning and demeaning of routine work. New York: Doubleday.

Geurts, K. L. (2002). Culture and the senses: Bodily ways of knowing in an African community. Berkeley: University of California Press.

Gimlin, D. (2007). What is 'body work'? A review of the literature. Sociology Compass, 1 (1), 353-370. 
Giorgi, A. (Ed.). (1985). Phenomenology and psychological research. Pittsburgh: Duquesne University Press.

Goodridge, J. (1999). Rhythm and timing of movement in performance. London: Jessica Kingsley.

Goodwin, C. (1994). Professional vision. American Anthropologist, 96, 606-633.

Goodwin, C. (1995). Seeing in depth. Social Studies of Science, 25, 237-274.

Griffiths, J., \& Mack, K. (2007). Going to sea: Co-creating the aesthetic dimension of shipboard organizational life. Culture and Organization, 13 (4), 267-281.

Hamilton, L. (2007). Muck and magic: Cultural transformations in the world of farm animal veterinary surgeons. Ethnography, 8 (4), 485-501.

Hassard, J., Holliday, R., \& Wilmott, H. (2000). Introduction. In J. Hassard, R. Holliday and H. Wilmott (Eds), Body and Organization (pp.1-14). London: Sage.

Heath, C., Luff, P., \& Sanchez Svensonn, M. (2002). Overseeing organisation. British Journal of Sociology, 53, 181-203.

Hetherington, K. (2003). Spatial textures: Places, touch and praesentia. Environment and Planning A, 35, 1933-1944.

Highmore, B. (2004). Homework. Routine, social aesthetics and the ambiguity of everyday life. Cultural Studies, 18 (2/3), 306-327.

Hinckley, J. (2005). The piano lesson: An autoethnography about changing clinical paradigms in aphasia practice. Aphasiology, 19 (8), 765-779

Hindmarsh, J., \& Heath, C. (2000). Sharing the tools of the trade: The interactional constitution of workplace objects. Journal of Contemporary Ethnography, 29, 517-56.

Hindmarsh, J., \& Heath, C. (2007). Video-based studies of work practice. Sociology Compass, 1 (1), 156-173.

Hindmarsh, J., \& Pilnick, A. (2002). The tacit order of teamwork: Collaboration and embodied conduct in anaesthesia. Sociological Quarterly, 43 (2), 139-164.

Hindmarsh, J., \& Pilnick, A. (2007). Knowing bodies at work: Embodiment and ephemeral teamwork in anaesthesia. Organization Studies, 28 (9), 1395-1416.

Howarth, G. (1996). Last rites: The work of the modern funeral director. Amityville, NY: Baywood Publishing.

Howes, D. (2003). Sensual relations. Engaging the senses in cultural and social theory. Anne Arbour: University of Michigan Press.

Howes, D. (2006). Charting the sensorial revolution. Senses and Society, 1 (1), 113-128.

Howson, A. (2005). Embodying gender. London: Sage.

Husserl, E. (1931). Ideas. Translated by W. R. Boyce Gibson. London: George Allen \& Unwin. 
Ingold, T. (2000). The perception of the environment: Essays on livelihood, dwelling and skill. London: Routledge.

Ingold, T. (2004). Culture on the ground: The world perceived through the feet. Journal of Material Culture 9, 315-340.

Junichi, M. (2005). Space and color: Toward an ecological phenomenology. Continental Philosophy Review, 38 (1-2), 1-17.

Kant, I. (1798) (1978). Anthropology from a pragmatic point of view. Translated by V. L. Dowdell. Carbondale \& Edwardsville: Southern Illinois University Press.

Katz, J. \& Csordas, T. J. (2003). Phenomenological ethnography in sociology and anthropology. Ethnography, 4 (3), 275-288.

Kerry, D. S., \& Armour, K. M. (2000). Sports sciences and the promise of phenomenology: Philosophy, method, and insight. Quest, 52 (1), 1-17.

King, A. (2006). The word of command: Communication and cohesion in the military. Armed Forces \& Society, 32 (4), 493-512.

Kondo, D. K. (1990) Crafting selves: Power, gender, and discourses of identity in a Japanese workplace. Chicago: University of Chicago Press.

Kupers, W. (2005). Phenomenology and integral pheno-practice of embodied well$\mathrm{Be}(\mathrm{com})$ ing in organizations. Culture and Organization, 11 (3), 221-232.

Lande, B. (2007). Breathing like a soldier: culture incarnate. Sociological Review, 55, Supplement 1, 95-108.

Largey, G. P., \& Watson, D. R. (1972). The sociology of odors. The American Journal of Sociology, 77 (6), 1021-1034

Laurier, E. (2008). How breakast happens in the café. Time and Society, 17 (1), 119134.

Lawler, J. (1991). Behind the screens: Nursing, somology and the problem of the body. Melbourne, Australia: Churchill Livingstone.

Leder, D. (1990). The absent body. Chicago: University of Chicago Press.

Linstead, S., \& Hopfl, H. (2000). The aesthetics of organization. London: Sage.

Luijpen, W. A. (1966). Phenomenology and humanism: Primer in existential phenomenology. Pittsburgh, P.A: Duquesne University.

Lynch, M. (2001). Ethnomethodology and the logic of practice. In T.R. Schatzki, K. Knorr Cetina \& E. Von Savigny (Eds), The practice turn in contemporary social theory (pp.131-148). London: Routledge.

Lyon, M. L. (1997). The material body, social processes and emotion: Techniques of the body revisited. Body \& Society, 3 (1), 83-101. 
Mack, K.S. (2007). Senses of seascapes: Aesthetics and the passion for knowledge. Organization, 14 (3), 373-390.

Martin, P. Y. (2002). Sensations, bodies, and the 'spirit of a place': Aesthetics in residential organizations for the elderly. Human Relations, 55 (7), 861-885.

Meerabeau, L., \& Page, S. (1998). 'Getting the job done': Emotion management and cardiopulmonary resuscitation in nursing. In G. Bendelow \& S. J. Williams (Eds), Emotions in social life: Critical themes and contemporary issues (pp. 295-312). London: Routledge.

Meier, K. V. (1988). Embodiment, sport and meaning. In W. P. Morgan \& K.V. Meier (Eds), Philosophic inquiry in sport (pp. 90-101). Champaign, II: Human Kinetics.

Merleau-Ponty, M. (1962). Phenomenology of perception. Translated by Smith, C. London: Routledge \& Kegan Paul.

Merleau-Ponty, M. (1969). The visible and the invisible. Translated by Lingis, A. Evanston, III: Northwestern University Press.

Mischenko, J. (2005). Exhausting management work: conflicting identities. Journal of Health Organization and Management, 19 (3), 204-218.

Moustakas, C. (1994). Phenomenological research methods. London: Sage.

Nichols, T., \& Beynon, H. (1977). Living with capitalism: Class relations and the modern factory. London: Routledge \& Kegan Paul.

O'Connor, E. (2007). Embodied knowledge in glassblowing: The experience of meaning and the struggle towards proficiency. Sociological Review, 55, Supplement 1, 126-141.

Paterson, K. and Hughes, B. (1999) Disability studies and phenomenology: the carnal politics of everyday life. Disability \& Society, 14 (5): 597-610.

Pollner, M., \& Emerson, R.M. (2001). Ethnomethodology and Ethnography. In P. Atkinson, A. Coffey, S. Delamont, J. Lofland \& L. Lofland (Eds), Handbook of Ethnography (pp.118-135). London: Sage.

Psathas, G. (1979). Organizational features of direction maps. In G. Psathas (Ed.), Everyday language: Studies in ethnomethodology. New York: Irvington.

Rodaway, P. (1994). Sensuous geographies: Body, sense and place. London: Routledge.

Rotella, C. (2002). Good with their hands. Berkley: University of California Press.

Salmon, P. (2002). Being at the receiving end: One patient's experience of nursing care. Auto/Biography, 10 (12), 107-112.

Sanders, P. (1982). Phenomenology: A new way of viewing organizational research. The Academy of Management Review, 7, 353-360.

Shakespeare, P. (2003). Nurses' bodywork: is there a body of work? Nursing Inquiry, 10 (1), 47-56. 
Sharma, U., \& Black, P. (2001). Look good, feel better: Beauty therapy as emotional labour. Sociology, 35 (4), 913-931.

Shilling, C. (2003). The body and social theory. London: Sage.

Shilling, C. (2007). Sociology and the body: classical traditions and new agendas. In C. Shilling (Ed.), Embodying sociology: Retrospect, progress and prospects (pp.1-18). Oxford: Blackwell/Sociological Review.

Smith, P.H. (2004). The body of the artisan. Chicago: Chicago University Press.

Sparkes, A. (Ed.) (2002). Telling tales in sport and physical activity. Champaign, II: Human Kinetics.

Strati, A. (1999). Organization and aesthetics. London: Sage.

Styhre, A. (2004). The (re)embodied organization: Four perspectives on the body in organizations. Human Resource Development International, 7 (1), 101-116.

Stoller, P. (1997). Sensuous scholarship. Philadelphia: University of Pennsylvania Press.

Sudnow, D. (1979). Talk's body: A meditation between two keyboards. New York: Knopf.

Synott, A. (1993). The body social: Symbolism, self and society. London: Routledge.

Taber, N. (2005). Learning how to be a woman in the Canadian Forces, unlearning it through feminism: An autoethnography of my learning journey 1. Studies in Continuing Education, 27 (3), 289-301.

Tangen, J. O. (2004). Embedded expectations, embodied knowledge and the movements that connect: A system theoretical attempt to explain the use and non-use of sport facilities. International Review for the Sociology of Sport, 39 (1), 7-25

Taylor, S. S., \& Hansen, H. (2005). Finding form: Looking at the field of organizational aesthetics. Journal of Management Studies, 42 (6), 1211-1231.

Theweleit, K. (1987). Male fantasies: Women, floods, bodies, history (Volume I). Minneapolis: University of Minnesota Press.

Todres, L. (2007). Embodied enquiry: Phenomenological touchstones for research, psychotherapy and spirituality. New York: Palgrave Macmillan.

Tuan, Y. F. (1993). Passing strange and wonderful. Washington, DC: Island PressShearwater.

Twigg, J. (2000). Bathing: The body and community care. London: Routledge.

Van den Berg, J.H. (1972). A different existence. Pittsburgh: Duquesne University Press.

Van Dongen, E., \& Elma, R. (2001). The art of touching: The culture of 'Body Work'. Anthropology and Medicine, 8 (2/3), 149-210. 
van Manen, M. (1990). Researching lived experience: Human science for an action sensitive pedagogy. New York: State University of New York Press.

Wainwright, S. P., \& Turner, B. S. (2006). Just crumbling to bits'? An exploration of the body, ageing, injury and career in classical ballet dancers. Sociology, 40 (2), 237-255.

Waskul, D., \& Vannini, P. (2006). Introduction: The body in Symbolic Interaction. In D. Waskul \& P. Vannini (Eds), Body/embodiment: Symbolic Interaction and the sociology of the body (pp.1-18). Aldershot: Ashgate.

Whalen, J., Whalen, M., \& Henderson, K. (2002). Improvisational choreography in teleservice work. British Journal of Sociology, 53, 239-258.

Willig, C. (2007). Reflections on the use of a phenomenological method. Qualitative Research in Psychology, 4, 209-225.

Willig, C. (2008). Introducing qualitative research in psychology $\left(2^{\text {nd }}\right.$ ed.). Milton Keynes: Open University Press/McGraw Hill.

Wolkowitz, C. (2002). The social relations of body work. Work Employment Society,16 (3), 497-510.

Wolkowitz, C. (2006). Bodies at work. London: Sage.

Woodward, R. (1998). It's a man's life!: Soldiers, masculinity and the countryside. Gender, Place, and Culture 5 (3), 277-300.

Young, I. M. (1998). 'Throwing like a girl': Twenty years later. In D. Welton (Ed.), Body and flesh: A philosophical reader (pp. 286-290). Oxford: Blackwell. 